\title{
Research on Implementing PLC Constant-pressure Water Supply Control Based on Modbus
}

\author{
Qu Zhan \\ Gansu Radio \& TV University \\ Lanzhou ,730000, China
}

\author{
Zhou Beibei \\ Gansu Agricultural University \\ Lanzhou 730070,China
}

\author{
Ren Yan \\ Gansu Radio \& TV University \\ Lanzhou ,730000, China
}

\begin{abstract}
PLC of the low layer of network in the paper communicates with field equipment by fieldbus or Modbus. And all PLC of the upper layer implements Ethernet hybrid network control system. The paper proposes a hybrid control network system based on PLC. The programmable controller TWDLCAE40DRF has the function of PID control on 13 parameters. So the programmable controller TWDLCAE40DRF can be used to control transducer to change the pressure value of water pipeline and maintain constant pressure of water pipelines. HMI is used to monitor the pressure of pipelines and adjust PID parameter in control.
\end{abstract}

Keywords-) Modbus, PLC, terminal, control

\section{INTRODUCTION OF MODBUS PROTOCOL}

Constant-pressure water supply is applied to civil drinking water network system, life and firewater system in residential area and cooling water recycle system of central air-conditioning in buildings. Constant-pressure water supply means that the client can keep water pressure of pipe network constant. In constant-pressure water supply system, the ideal value signal is compared with feedback signal of water pressure of pipe network. According to the compared structure, the frequency convertor adjusts the rotation rate of water pumps to achieve the objective controlling water pressure of pipe network. The paper introduces the design method of PLC control frequency conversion constant pressure water supply system based on Modbus.

Industrial control is transforming into central control and distributed control from single-machine control. In the network age, the networking industrial controller makes network management easy.

Modbus is one of network protocols in industrial controllers. Modbus protocol is a common language of electronic controllers. By the protocol, the client/server communication is provided by the controller through network and other equipment.

Modbus is the message transmission protocol of application layer of OST model. Modbus protocol defines whatever network is for communication, a controller can recognize the applied message structure. It describes the process of a controller requesting access to other equipment, how to respond the request from other equipment and how to detect error and record. It formulates the pattern of message domain and common format of content. When the communication is made on Modbus network, the protocol determines that each controller needs to know device address, identify the message which is sent based on address, and determines the actions. If it needs response, the controller generates feedback information and uses Modbus protocol to send the message. The other networks include the frame or package structure for message transformation of Modbus protocol. The transformation extends the methods of solving address, routing path and error detection according to network.

\section{INTRODUCTION OF FREQUENCY-CONVERSION AND CONSTANT-PRESSURE WATER SUPPLY}

\section{A. Introduction of frequency-conversion and constant- pressure water supply}

The control strategy of constant-pressure water supply control system is as follows. The speed regulation device of electrical motor and programmable controller (PLC) are used to compose control system, which not only can optimize the control on speed governing operation of pumping set, but also automatically adjusts the operated pump governors to realize closed-loop control of watersupply pressure, which achieves the object of stabilizing water-supply pressure and saving electric power when the flow of pipe network changes. The control objective of the system is effluent discharging pressure of the header pipe of pumping station. The given water-supply pressure value and the actual pressure value of the header pipe is compared. After the difference is input CPU for operation, the control command is sent to control the pump motors and operate the rotation rate of variable pumps, which makes water-supply pressure of the header pipe keep the given pressure value.

The speed control device of electrical motor for automatic constant-pressure water supply system applies $\mathrm{AC}$ frequency conversion technology, and the control device of the system uses PLC controller. PLC not only can realize logic control of pump unit and valve, and can complete digital PID regulation of system, but also can monitor operations parameters and control points in the system, and complete picture plane display, failure alarm and printing reports of the system operation. Automatic constant-pressure water supply system has standard communication interface. It can interconnect with the upper computer of civil water 
supply system to realize optimized control of urban water supply system, which provides modernized scheduling, management, supervision and economic operation for civil water supply system.

\section{B. Characteristics of frequency-conversion and constant- pressure water supply}

[1] It saves energy, and can realize saving $20 \%-40 \%$ of electricity, which can realize green electricity use.

[2] It occupies a limited area, the investment is little and the efficiency is high.

[3] The configuration is flexible, the automaticity is high, and the functions are completed.

[4] The operation is rational. Soft start up and soft stop not only can eliminate water hammer effect, but also can reduce average torque and wear of motor shaft and reduce repair cost, and improve the life of pump.

[5] Communication control can realize unattended operation, which saves human and material resources.

\section{From the working principle of pumps, we can get the theory of energy efficiency}

as follows. The flow of pump is proportional to the rotation rate of pump, the lift of pump is proportional to the square of rotation rate of pump, and the shaft power of pump is equal to the product of flow and lift, so the shaft power of pump is proportional to the cube of lift and rotation rate of pump. According to the above principle, we can see that the rotation rate of pump can change the power of pump.

The formula of low is,

$$
\begin{aligned}
& Q \propto n ; \\
& H \propto n^{2} \\
& P \propto(Q \times H) \propto n^{3},
\end{aligned}
$$

In the formula, $\mathrm{Q}$ means flow, $\mathrm{n}$ means rotation rate, $\mathrm{H}$ means lift and $\mathrm{P}$ represents shaft power. For example, the power supply frequency reduces to $45 \mathrm{~Hz}$ from $50 \mathrm{~Hz}$, and $P 45 / P 50=(45 / 50)^{3}=0.729$ or $45=0.729 \times \mathrm{P} 50$. When the power supply frequency reduces to $45 \mathrm{~Hz}$ from
$50 \mathrm{~Hz}$, the objective saving energy can be realized when the power of pump can reduce by 0.729 times of the power of $50 \mathrm{~Hz}$.

Pump is considered according to the situation of water supply system, but water system can't reach the maximum discharge of water in practice. It is common to use valves to adjust resistance of system for throttle, which makes electricity consumption loss of electronic motor. But using frequency converter can make the working state of system stable. And it can adjust water supply by changing rotation rate, and can recoup the capital outlay by reducing rotation rate.

\section{Applications of frequency-control and constant- pressure water supply equipment}

[1] Domestic water of buildings, urban residential areas and enterprises.

[2] The industry needs the water of constant pressure control. Cooling water circulation, heat network water circulation and boiler water.

[3] Central air conditioning system

[4] Pressure charging system of water treatment plant

[5] Agricultural irrigation, wastewater treatment and fountain.

[6] Various fluid constant pressure control system.

\section{E. Frequency converter ATV 31 state transmission diagram}

Figure 1 is frequency converter state transmission diagram. The control word CMD is used to start, stop and set frequency, which can convert a state of the frequency converter into the other state. It is very important to know the control word of frequency converter and register number of parameters. After state word ETA frequency converter receives state word, the correlation is made according to the defined objectives. And the corresponding relationship can refer to the instruction of frequency converter. 


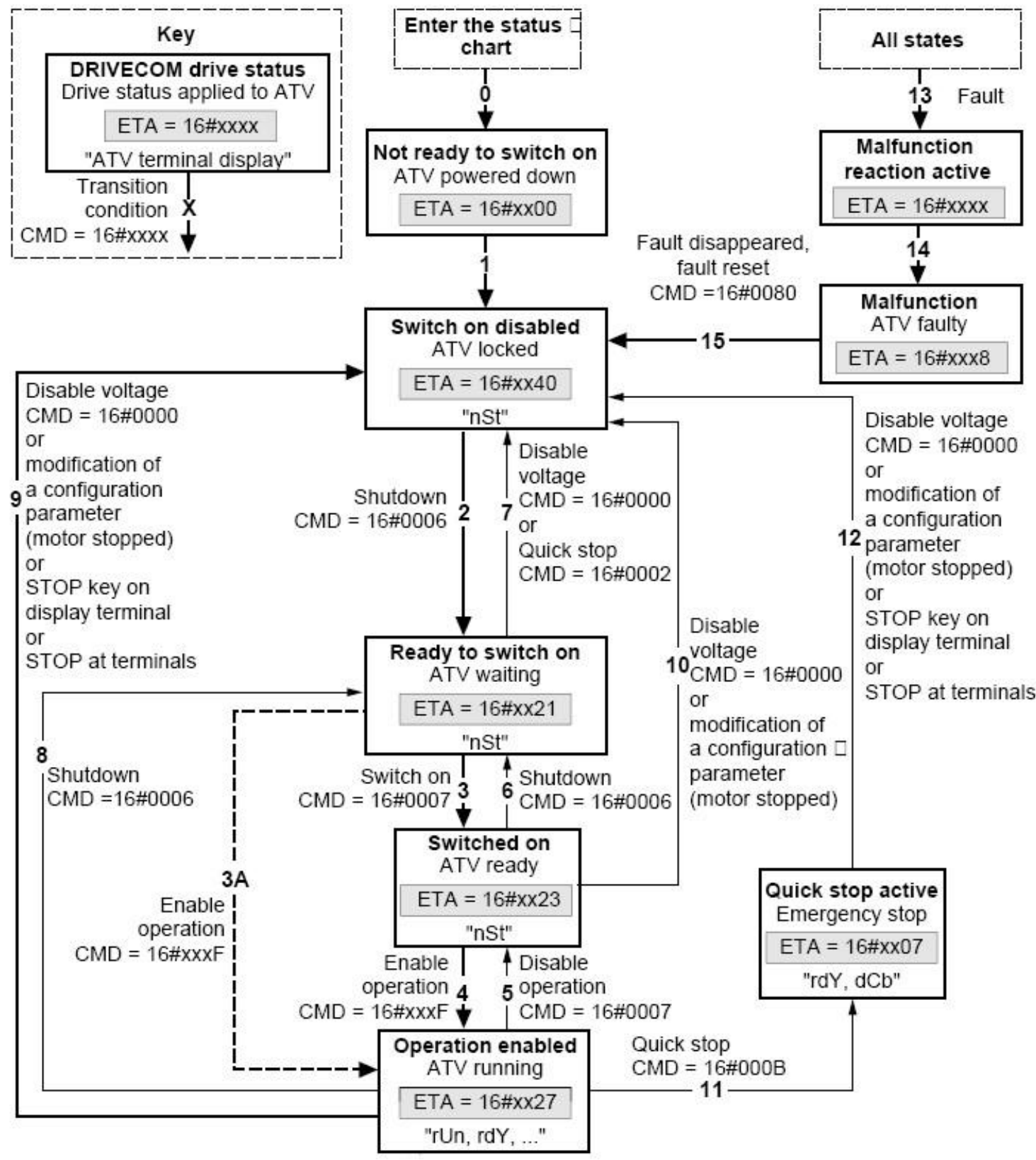

Figure 1 Frequency converter state transmission diagram

The following is the instructions of ATV 31 frequency converter of Schneider Electric. The command word CMD (register number W8501), and the state word ETA (register number W3201).

\section{FREQUENCY CONVERTER CONSTANT-PRESSURE WATER SUPPLY LABORATORY MODEL}

Small PLC of Twido series in Schneider Electric has the characteristics of convenience, reliable performance and low price. The internal Modbus communication protocol is applicable for ATV31 frequency-conversion and constantpressure control system. The master controller uses PLC of

Twido series, TWDLCAE40DRF, and it is integrative with 24 routes, 14 relay output, 2 transistor output, 1 100BaseTX Ethernet, 1 RS485 serial port and 1 extended port, and it supports the communication of TCP or Modbus. 14-route PID has self-tuning function. The operation speed is 0.14 microsecond of each listing directive, and it can extend digital or analog signal module.

It is easy to apply Twido series of PLC and HMI to implement real-time communication on ATV31 of Schneider Electric. The user only needs to operate on HMI, which can 
modify and display some parameters of frequency converter such as pressure rate capacity, given pressure setting, starting frequency converter, stopping slope, malfunction alerting and pressure feedback value display.

ATV31 frequency converter can communicate with Twido PLC by Modbus. The control signal of ATV31 frequency converter can be from Modbus serial communication. The system composition is shown in Figure 2.

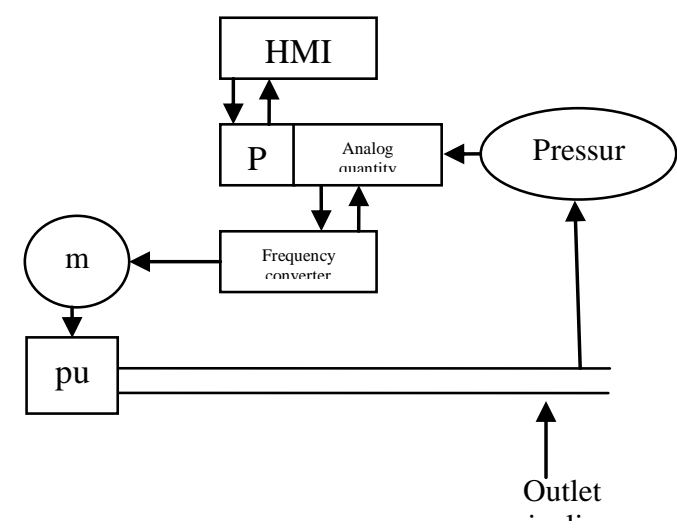

Figure 2 Control system chart

The paper uses the programmable controller TWDLCAE40DRF of Schneider Electric. The controller can extend analog quantity moduleTWDAMM6HT with 4 analog inputs and 2 outputs, and the address is 1. As a controller, PLC controls analog quantity module and frequency converter ATV31 for data exchange by Modbus. Frequency converter makes water pressure of outlet pipeline keep consistent with the setting value according to rotation rate of water pressure control motor.

In the frequency converter constant-pressure water supply model based on PLC, the frequency converter is the core of frequency-conversion and constant-pressure water supply system. The principle of frequency converter constant-pressure water control is shown in Figure 3. In figure 3 , the pump motor is the output component, and the rotation rate is controlled by frequency converter, which realizes constant pressure control. The frequency converter receives the signals of PID controller and controls the speed of pump. The pressure sensor detects the outlet pressure of pipe network. PID controller is used to adjust the frequency of frequency converter to control the rotation rate of pump, which realizes a closed-loop control. Twido Soft can set PID parameter, which can achieve the objective of PID control. In field control circuit, the variation of disturbance may cause the jumping of field vale. PID control eliminate the disturbance to make the system stable as soon as possible, in the process of designing the system, not only speed regulation system can be designed, but also the periodic disturbance signals can be added artificially.

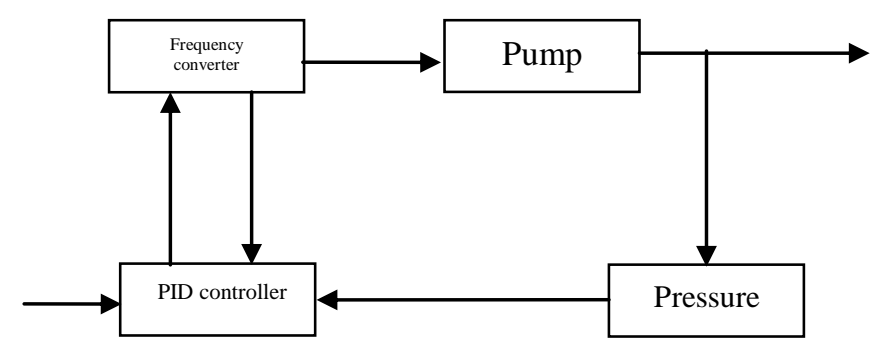

Figure 3 PID control principle of frequency-conversion and constant-pressure water supply

The module configuration of analog quantity is shown in Figure 4.

\begin{tabular}{|c|c|c|c|c|}
\hline \multicolumn{5}{|c|}{ Analog Module Configuration - TWDAMMGHT [Position 1] } \\
\hline $1 \% 1 W 1.0$ & $10-10 \mathrm{~V}$ & Nornal & 0 & 4095 None \\
\hline $1 \%$ IW1.1 & Not Used & Nonnal & 0 & 4095|None \\
\hline $1 \% 1$ IW1.2 & $0-10 V$ & Nornal & 0 & 4095|None \\
\hline $1 \% 1$ II. 3 & Not Used & Nonnal & V & 4095|None \\
\hline $1 \% 0 \pi 1.0$ & Not Used & Nornal & 0 & 4095 None \\
\hline $1 \% 0 \pi 1.1$ & $0-10 \mid$ & |Nonal & 0 & 4095|None \\
\hline
\end{tabular}

Figure 4 Analog module configuration

PID configuration is shown in Figure 5. The parameters of PID are set for programming. In the actual commissioning process, the parameters of PID can be directly input by HMI, which is easy for debugging. 


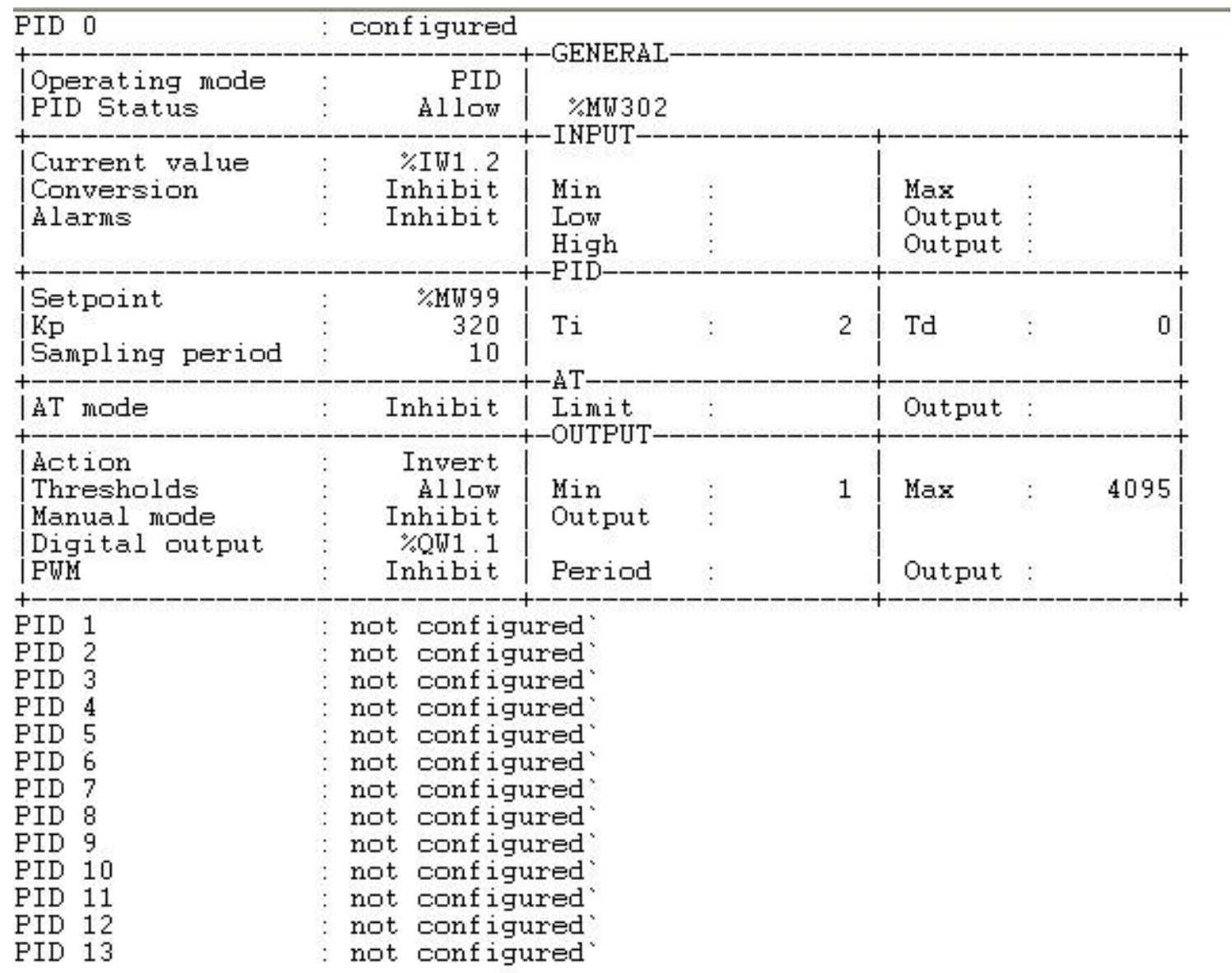

Figure 5 PID configuration

In the control process, PLC and frequency converter exchange data. A pressure value is set for the frequency converter and the frequency converter feedbacks PLC value to pressure sensor. And the data exchange process is shown in Figure6.

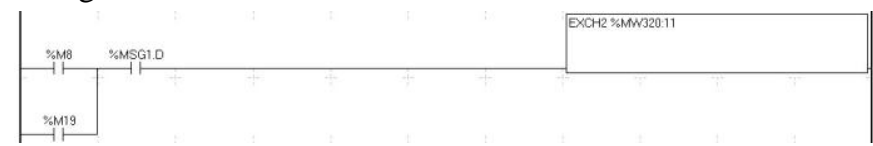

Figure6 Data exchange program

\section{Conclusions}

In the paper, PLC based on Modbus implements the rotation rate of frequency converter control motor to realize constant-pressure control. And it includes the regulation of PID, artificial addition of interference signal and simulation of actual process. It is widely applied in real life.

\section{Reference}

[1] Hart Publishing. DOUBLERANGE LTD AND OTHERS v (1) NATIONAL POWER PLC (2) POWERGEN PLC; AND BRITISH COAL CORP (THIRD PARTY) (1) HARRIS AND THOMAS (2) AMAN MINING LTD v B (1) NATIONAL POWER PLC (2)
POWERGEN PLC[J]. European Law Reports of Cases in the United Kingdom and Ireland,1997,15:.

[2] Hart Publishing. (1) Abbey National Plc (2) Barclays Bank Plc (3) Clydesdale Bank Plc (4) Hbos Plc (5) HSBC Bank Plc (6) Lloyds Tsb Bank Plc (7) Nationwide Building Society (8) the Royal Bank of Scotland Group Plc v The Office of Fair Trading[J]. European Law Reports of Cases in the United Kingdom and Ireland,2010,141:.

[3] Anonymous. Royal Dutch Shell plc; Royal Dutch Shell Plc: Peter Voser to be Next Chief Executive of Royal Dutch Shell plc[J]. Science Letter,2008,:

[4] Anonymous. Research and Markets: Dairy in The United Kingdom Features Leading Companies Arla Foods UK Plc, Dairy Crest Group Plc and Glanbia Plc[J]. M2 Presswire,2009,:.

[5] Anonymous. TTP Group plc; TTP Group Plc Buys Back Its Shares from 3I Plc[J]. Journal of Technology,2009,:

[6] Anonymous. Research and Markets: M\&C Saatchi Plc Versus Mission Marketing Group Plc (The), Media Square plc and Ten Alps PLC[J]. M2 Presswire,2009,:.

[7] Nicholas O'Regan,Abby Ghobadian. A serial successful strategic transformer of businesses: An interview with Anthony Habgood, Chairman of Whitbread plc, Reed Elsevier plc and former CEO and Chairman, Bunzl plc[J]. Journal of Strategy and Management,2010,31:

[8] Anonymous. WIN plc: WIN plc Launches Applications For Vodafone 360; WIN plc launches three new applications for the platform[J]. M2 Presswire,2010,:. 